\title{
Innovación Educativa en la Enseñanza de la Electrónica
}

\author{
J.M. Andujar, C. García, M.J. Redondo y J. Aroba \\ Universidad de Huelva, Escuela Politécnica Superior, Departamento de Ingeniería \\ Electrónica, Sistemas Informáticos y Automática, Carretera Palos de la Frontera s/n, \\ 21089 La Rábida (Palos de la Frontera), Huelva-España
}

\begin{abstract}
Resumen
Se discuten y analizan algunas de los métodos más comunes sobre enseñanza-aprendizaje usados en cursos de electrónica. La discusión se centra en la eficiencia de los métodos para transmitir conceptos a los estudiantes. Se discute sobre las principales ventajas y desventajas de las técnicas audiovisuales (imágenes, fotografías, sonido, videos y animaciones), de las aplicaciones de computación, y de los experimentos de laboratorio. El artículo propone un método que incluye estas tres técnicas y se aplica la propuesta al montaje de un circuito electrónico. Se concluye que con videos y animaciones, además de confeccionar aplicaciones atractivas que motivan al alumno, se pueden mostrar procesos que resultarían imposibles de describir con imágenes estáticas solamente.
\end{abstract}

\section{Educational Innovation in the Teaching of Electronics}

\begin{abstract}
Some of the common teaching-learning methods used in electronic courses are discussed and analyzed. Discussion is centered on the efficiency of the methods used to transmit concepts to the students. The main advantages and disadvantages of audiovisual techniques (images, photographs, sound, video and animation), computer applications, and laboratory experiments, are discussed. The article proposes a method which includes these three techniques and is applied to the assembling of an electronic circuit. It is concluded that with videos and animations, besides making attractive applications to motivate students, one can show processes that would be impossible to show using static images only.
\end{abstract}

Keywords: electronics teaching, electronic circuits, audiovisual techniques

Nota: este artículo está tomado de "Información Tecnológica" [ISSN 0716-8756], vol. 9(2), 329-334 (1998) 


\section{INTRODUCCIÓN}

El presente artículo aporta algunos mecanismos que se han aplicado a la enseñanza de la electrónica en el Departamento de Ingeniería Electrónica, Sistemas Informáticos y Automática en la Escuela Politécnica Superior de la Universidad de Huelva, concretamente en asignatura de Instrumentación, Técnicas de Medida y Mantenimiento, correspondiente al tercer curso de Ingeniería Técnica en Informática de Sistemas. Se han aplicado a la materia filtros activos, dentro de la asignatura anteriormente mencionada, como experiencia piloto en el curso 1995/1996. Básicamente, consiste la idea de complementar la explicación técnica con una serie de imágenes dotadas de sonido (elementos llamados multimedia según Charte, 1995 y Shaddock, 1995), que reflejan los tópicos de la materia en cuestión.

\section{METODOLOGÍA}

Se describen los recursos empleados para una mejor comprensión de la materia de filtros activos, por parte de los alumnos de la asignatura bajo estudio.

\section{Sistemas Multimedia}

Debido a la tradicional dificultad de los alumnos para asimilar la materia correspondiente al tema de filtros activos de pensó en la elaboración de un sistema multimedia que complementase las explicaciones teóricas tradicionales. Dicho sistema se compone de una serie de imágenes, cada una de las cuales representa una idea básica a transmitir por el profesor, como puede ser la indicada en la figura 1, en la cual se pretende que el alumno vea a nivel ideal la diferencia existente entre los distintos tipos de filtros. Las imágenes antes mencionadas se hallan almacenadas en un soporte magnético y son tratadas mediante el software adecuado. Dicho software permite realizar una serie de tareas, tales como avanzar imágenes, retroceder, acceder a una imagen directamente, mostrar varios en pantalla, imprimirlas, grabarlas, etc.

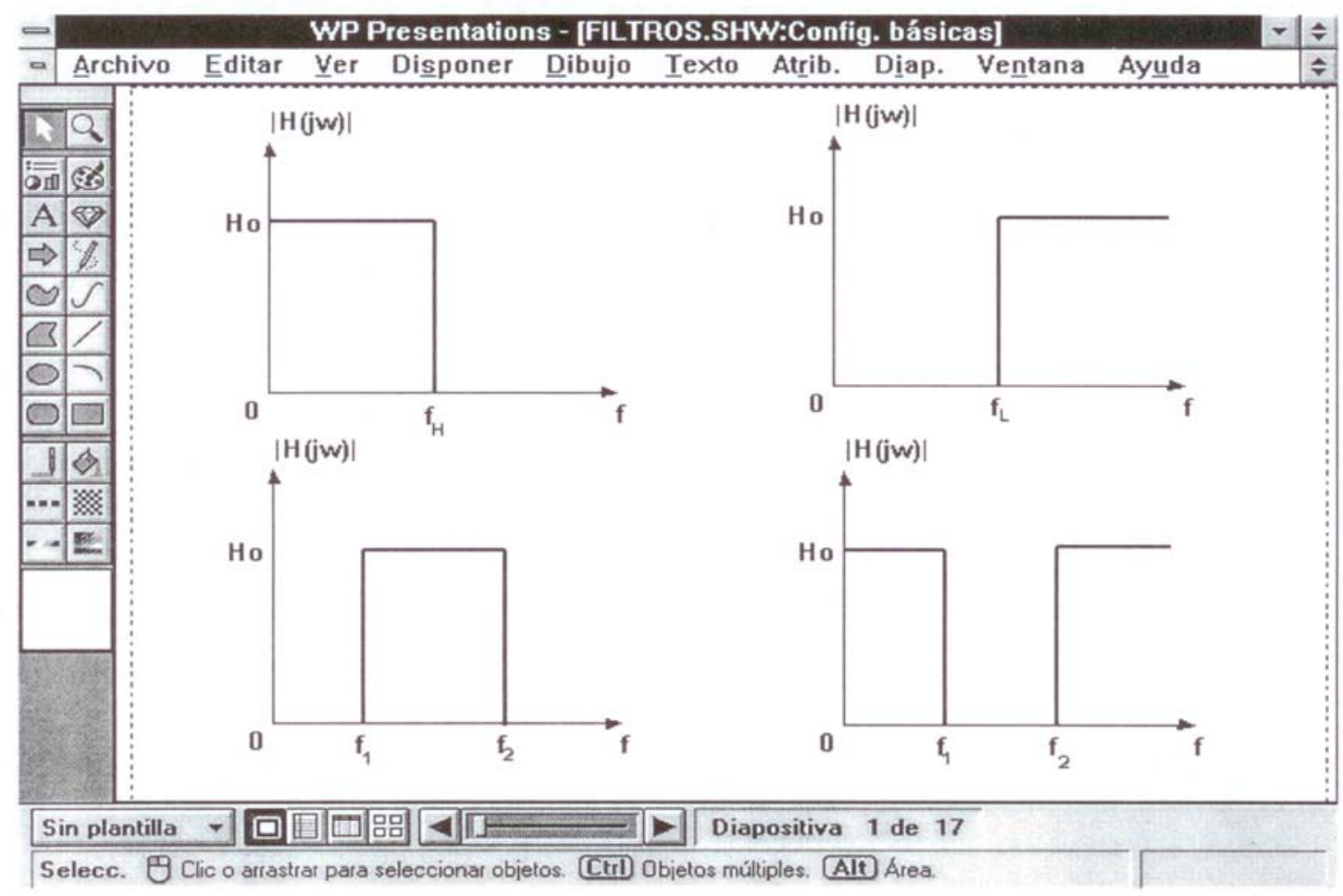

Fig. 1: Comparación de respuestas ideales de distintos tipos de filtros.

Como modelo de software se ha empleado en la fase inicial la aplicación llamada WP Presentations $\AA^{\circledR}$ la cual, además de todo ello, permite también asociarle un sonido a cada imagen, retocar la imagen sobre la marcha, etc. Además, el hecho de ejecutarse bajo entorno Windows ${ }^{\mathrm{TM}}$ 
permita que pueda utilizarse el puntero del ratón como señalador, apoyando las posibles notas que pueda hacer en la imagen (ver figura 2). En dicha figura, descrita por Williams (1981), también se aisla la respuesta de un filtro de las demás para estudiarla más en profundidad y resaltar los aspectos de ella.

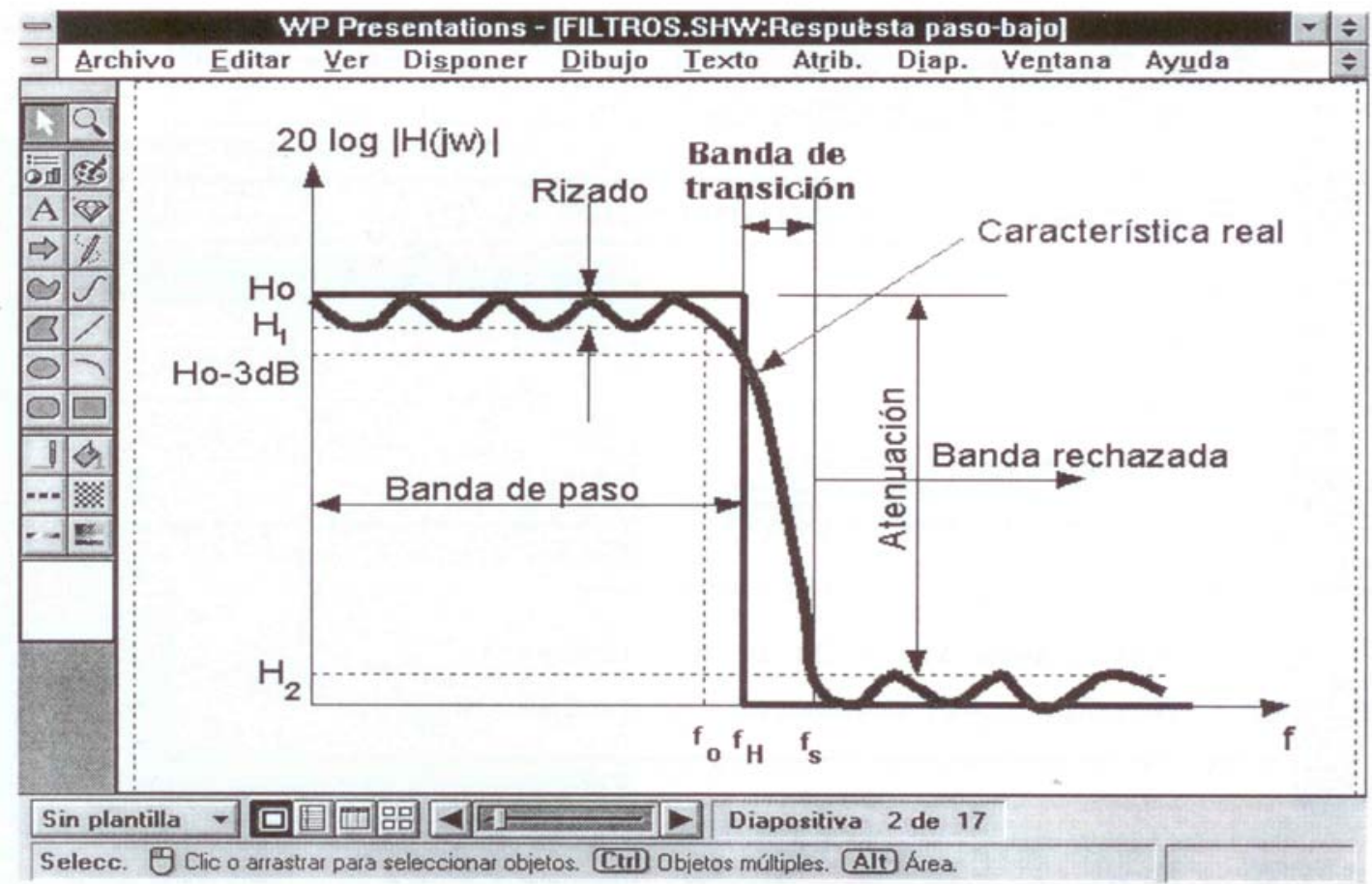

Fig. 2: Respuesta paso-bajo real.

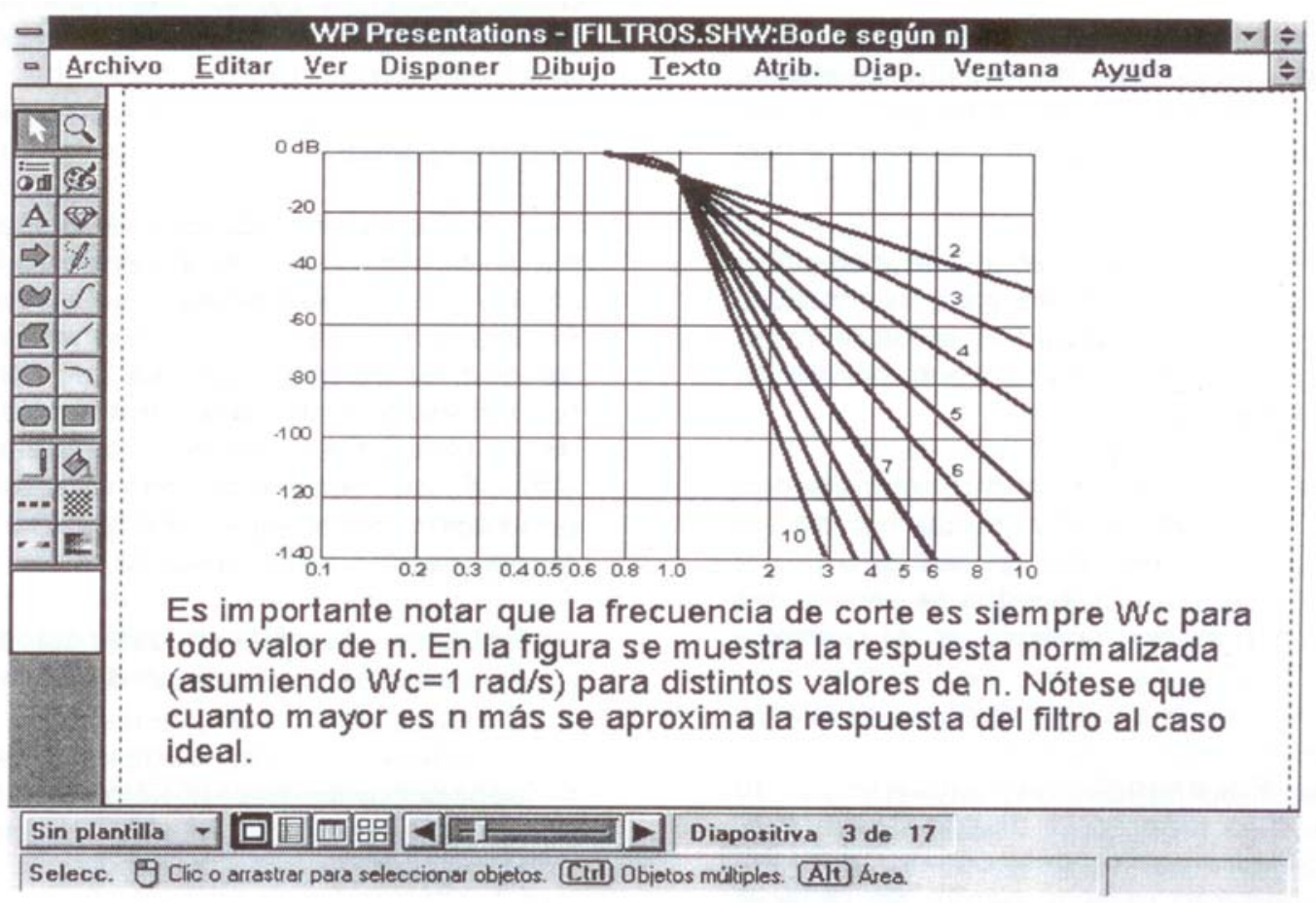

Fig. 3: Respuesta del filtro de paso-bajo en función del orden.

Como puede verse en la figura 3, la existencia de un texto explicativo que acompaña al sonido puede hacer un doble impacto en la mente del alumno. También se pueden mostrar ecuaciones 0 tablas interesantes, como las de la figura 4. 
Es muy fácil realizar una presentación en la que se pueden ver detalles interesantes de varias imágenes, tal como la ecuación de un filtro paso-bajo a la vez que el esquema del circuito electrónico que lo realiza y su respuesta en frecuencia

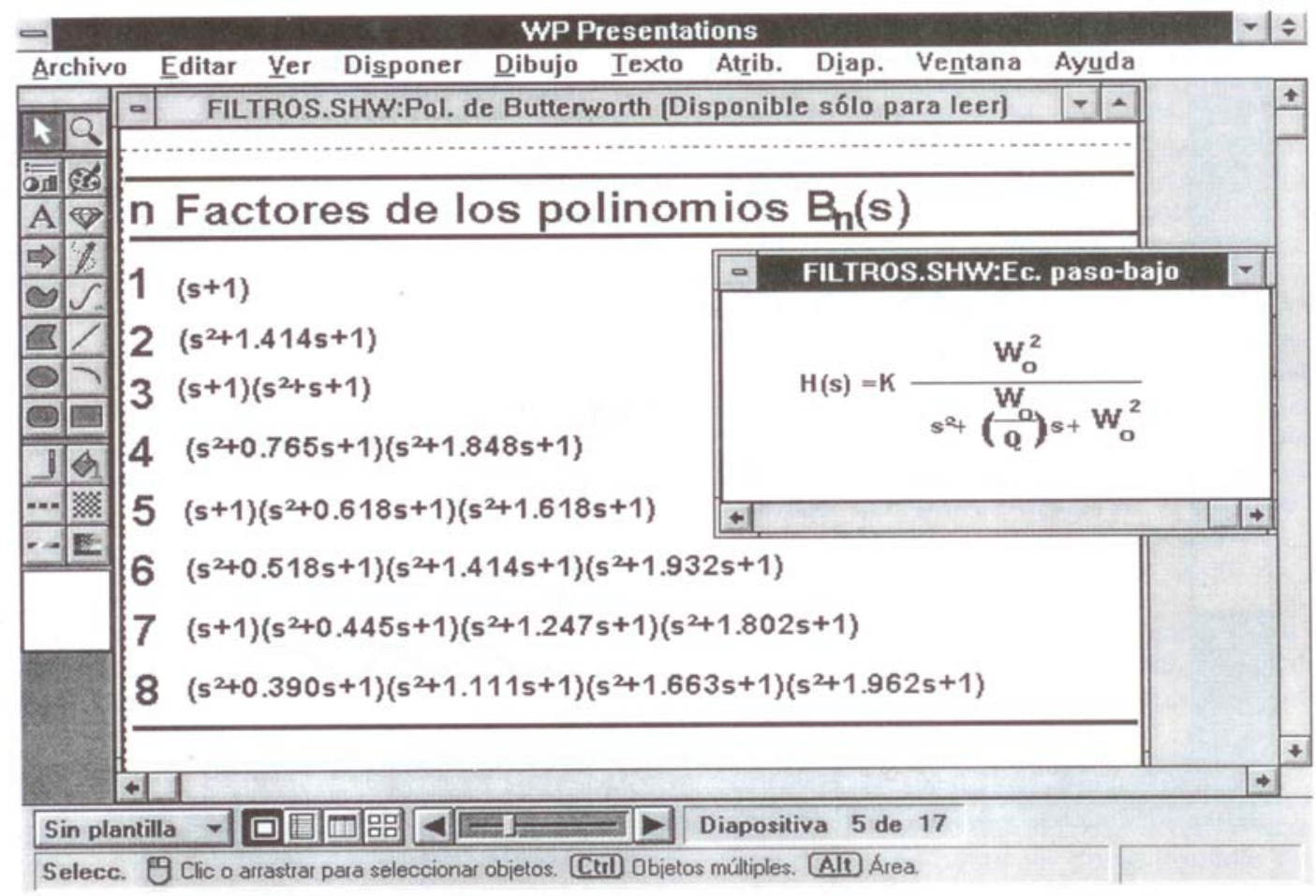

Fig. 4: Polinomios de Butterworth y función de transferencia del filtro paso-bajo.

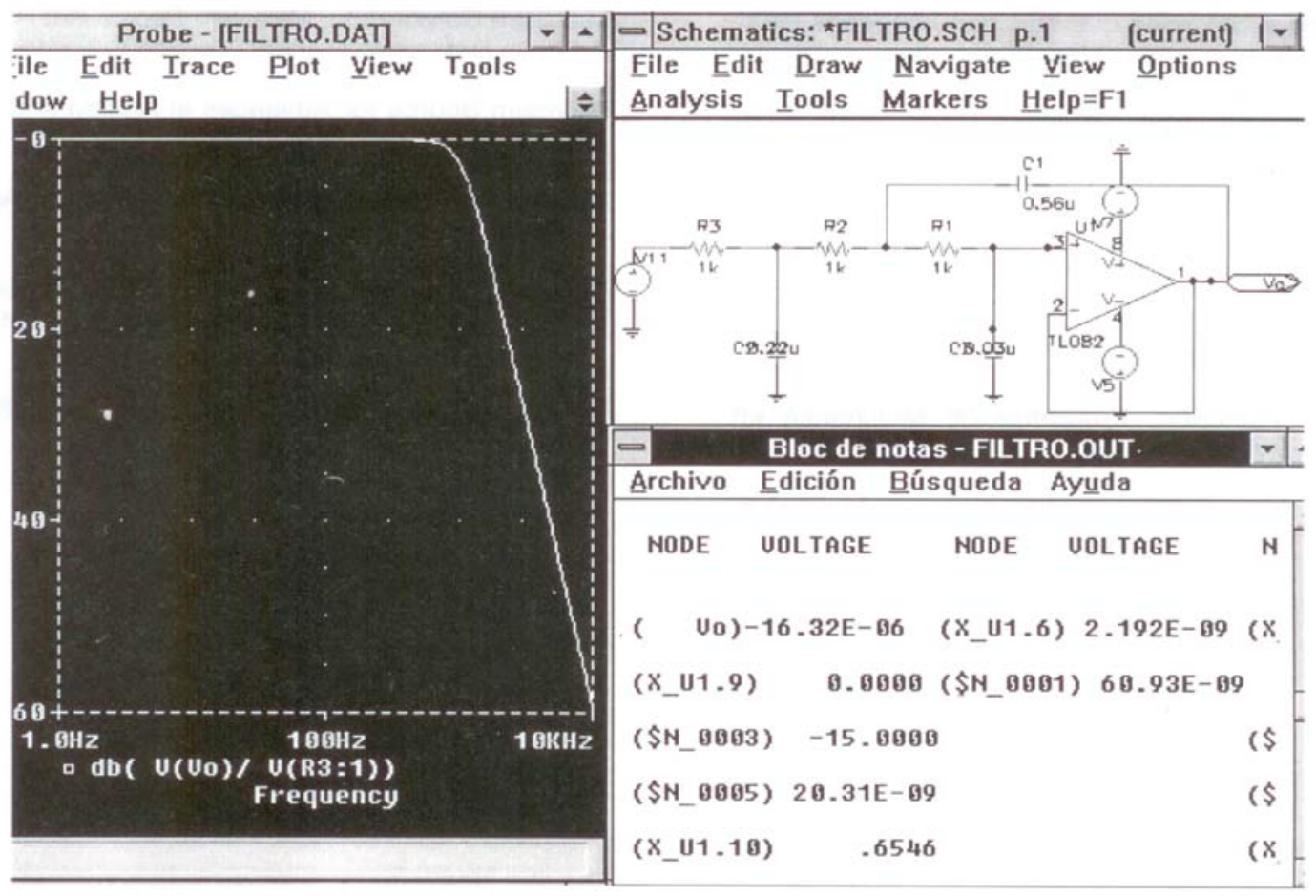

Fig. 5: Ejemplo de utilización del simulador.

\section{Simulación por Ordenador}

Como complemento básico a las clases teóricas se pensó en la utilización de alguna herramienta que permitiera a los alumnos comprobar el correcto funcionamiento de un diseño real antes de 
pasar a la realización física en el laboratorio. La aplicación utilizada ha sido el simulador de circuitos Pspice ${ }^{\mathrm{TM}}$, ya que además de permitir todo tipo de simulaciones, analógicas, digitales y mixtas (Tuinenga, 1992; Bashir, 1995; Larney, 1995; Microsim, 1995, 1996) constituye probablemente el simulador más aceptado en las Universidades españolas y extranjeras.

Mediante el simulador, casi todos los ejercicios se realizan con el ordenador, ya que además de introducir una motivación adicional en el alumno, permite ahorrar tiempo y ganar precisión en los cálculos. Si a todo lo anterior se le une la utilización de un editor gráfico de esquemas para la introducción del circuito en el computador, el alumno no necesita escribir código para proporcionarle la entrada al simulador.

También se pueden comparar algunos aspectos de la simulación con el contenido de las imágenes, lo cual se puede ver en la figura 5 . Un beneficio que se obtiene por añadidura, es que los estudiantes pueden hacer hincapié en el comportamiento de la red, tarea que de hacerse manualmente, se vuelve realmente tediosa debido a las operaciones matemáticas para obtener dicho comportamiento. Por ejemplo, un estudiante puede emplear una hora o más en el diseño de un filtro de $5^{\circ}$ orden. Seguramente, después de ese esfuerzo, no le quedarán nuevas ganas de rehacer los cálculos para saber qué pasa si cambian algunos de los parámetros del circuito. Mediante el simulador, la repetición del diseño con los nuevos parámetros le llevará como mucho un minuto.

Además hay que tener en cuenta el hecho de que se pueden reproducir condiciones reales (temperatura, tolerancia de componentes, modelos comerciales, etc.), lo cual permite optimizar el diseño asegurando el buen funcionamiento del montaje físico.

\section{RESULTADOS Y DISCUSIÓN}

Considerando que, al menos en el Departamento, se encuentra en los inicios de la aplicación de la multimedia a la enseñanza de la Electrónica, se ha de reconocer que la experiencia que se muestra aquí ha resultado gratamente reconfortante y provechosa, no sólo valorable desde el punto de vista del rendimiento académico obtenido por el alumno, sino desde la motivación y entusiasmo mostrados. En general, los beneficios obtenidos se pueden resumir en:

- Énfasis y atención en ideas clave.

- Aumento en la retención de información.

- Clasificación y comprensión de las ideas más complejas y que, tradicionalmente, han sido peor captadas por los alumnos.

- Hacer interactiva la clase, logrando una efectiva participación de los alumnos.

Desde hace algún tiempo los docentes han usado diferentes medios para dar apoyo a lo que podrían denominarse clases convencionales. Entre estos medios sobresalen los audiovisuales que, integrados en soporte informático, configuran los sistemas denominados multimedia. La idea en el Departamento es, apoyándose en la experiencia adquirida, intentar aglutinar todos los componentes que conforman la clase, incluido el laboratorio, en soporte óptico con animación y sonido desde un punto de vista totalmente interactivo.

El intento de llegar más allá obliga a elegir otro modelo de software más versátil. Ahora no sólo nos vamos a conformar con tener textos, gráficos y sonido, sino que se hace necesaria la inclusión de animaciones, videos y otros elementos que hagan que las ideas que el alumno recibe lleguen con una nitidez cristalina.

Como herramienta que permita desarrollar las aplicaciones necesarias, se ha tomado la decisión de usar Asymetrix TM Toolbook. Son muchas las ventajas que proporciona la utilización de este tipo de herramientas, pero la principal es que incorpora una plataforma completa de programación multimedia en entorno Windows, además de todas las posibilidades de visualización expuestas en epígrafes anteriores. Esto va a permitir desarrollar aplicaciones autónomas y cerradas, a las cuales podemos dotar de todos los elementos necesarios para que cumplan su cometido. 
Asymetrix ${ }^{\mathrm{TM}}$ ToolBook es sólo una herramienta de desarrollo, por lo que las aplicaciones que se elaboran pueden ser distribuidas. Esto no podía hacerse antes, ya que para ello se necesitaba la licencia de terceras partes, lo que implicaba un elevado costo. Además, WP Presentations ${ }^{\circledR}$ es una aplicación comercial de propósito general para diseño de presentaciones y deberíamos distribuir toda la aplicación para utilizar sólo una pequeña parte de sus posibilidades.

Una nueva posibilidad es la inclusión e los programas de unos test de autoevaluación, con lo que el alumno podrá llevar un control de sus progresos en asignatura. Dichos test podrán ser almacenados en bases de datos y, por lo tanto, podrían ser objeto de modificaciones periódicas.

\section{CONCLUSIONES}

En los programas multimedia se pueden incluir imágenes, fotografías, sonido, videos y animaciones. Con estos dos últimos elementos, además de confeccionar aplicaciones muy atractivas que motiven al alumno, se pueden mostrar determinados procesos que sólo con imágenes estáticas resultarían imposibles de describir. En definitiva, son ideas que se están desarrollando en el Departamento y cuya finalidad no es otra que aumentar en lo posible la calidad de docencia.

\section{REFERENCIAS}

Bashir Al-H.; The Art of Simulation Using Pspice: Analog and Digital. CRC Press, Inc (1995)

Charte, F.; Programación Multimedia en Windows, Anaya (1995)

Lamey, R.; The Illustrated Guide to Pspice. Delmar Publishers, Inc (1995)

Microsim Corporation. Microsim Pspice A/D, Curcuit Análisis Reference Manual. Version $6.2,(1995)$

Microsim Source for Advances in Anolog and Digital Design, January 1996

Shaddock, P.; Creaciones Multimedia. Anaya (1995)

Tuinenga, P.W.; Spice: A Guide to Circuit Simulation and Analysis Using Pspice. Prentice Hall (1992)

Williams, A.B.; Electronic Filter Design Hand Book, McGraw.Hill (1981) 